\title{
MORPHOLOGY AND MOVEMENT OF THE PRESACRAL VERTEBRAL COLUMN IN PHENACODUS VORTMANI AND PHENACODUS PRIMAEVUS
}

OTTS, Charlotte, Dept. of Biology, Chemistry and Environmental Sciences, Christopher Newport College, 50 Shoe Lane, Newport News, VA 23602 U.S.A.

Phenacodus vortmani and $\underline{\mathrm{P}}$. primaevus, members of the mammalian radiation (Tiffanian - Bridgerian) in western North America, were digitigrade fivetoed ungulates who were good runners compared to their contemporaries. $\underline{P}$. vortmani was smaller and more slender (presacral vertebral column $=463 \mathrm{~mm}$ ) while $\underline{P}$. primaevus was larger and more robust (presacral vertebral column $=$ $814 \mathrm{~mm}$ ).

The presacral vertebral column in these phenacodontids consists of 7 cervical, 15 thoracic, and 6 lumbar vertebrae, with the sectional length proportions being very similar in $\underline{P}$. vortmani and $\underline{P}$. primaevus.

Morphologies and relationships of the vertebral structure in the cervical section allow both dorsoventral and mediolateral movements in both animals. Structures in the cranial thoracic section allow some mediolateral movement but restrict dorsoventral motion, adding stability and allowing forward transfer of momentum generated in the hind limb and caudal vertebral column. Structures in the caudal thoracic and especially the lumbar sections allow greater dorsoventral movements which enabled both phenacodontids to increase stride length beyond that accomplished by the limbs alone. In the smaller $\underline{P}$. primaevus, the orientation of the zygapophyses emphasizes dorsoventral movements and restricts mediolateral movements compared to that in $\underline{\mathbf{P}}$. vortmani, providing the larger animal with greater efficiency in the flexion and extension of the posterior vertebral column during running. 